\title{
A influência dos fatores genéticos sobre a etiologia da hipomineralização molar-incisivo: revisão de Literatura
}

\author{
The influence of genetic factors on the etiology of molar-incisor hypomineralization: \\ literature Review
}

La influencia de los factores genéticos en la etiología de la hipomineralización de los incisivos molares: revisión de la literatura

\begin{abstract}
Lucas Lino de Oliveira ${ }^{1 *}$, Felipe Raoni dos Santos Freitas ${ }^{2}$, Henrique Cabral de Sá1, Larissa da Silva Bezerra ${ }^{1}$, Maria Priscylliana de Fátima Arcelino Couto ${ }^{1}$, Nadine Pinheiro Linhares ${ }^{1}$, Priscila Barbosa Ferreira $^{1}$, Zidane Hurtado Rabelo ${ }^{1}$, Mariana Vasconcelos Guimarães ${ }^{1,3}$, Vilana Maria Adriano Araújo ${ }^{1,3}$.
\end{abstract}

\section{RESUMO}

Objetivo: Verificar a influência dos fatores genéticos sobre a etiologia da Hipomineralização Molar-Incisivo (HMI). Métodos: Pesquisaram-se os descritores cadastrados no MeSH "genetics", "dental enamel hypoplasia", "molar" e "incisor" na base de dados Pubmed, conectados pelo operador booleano "AND". No período entre 2009 a 2019, encontraram-se 15 estudos, dos quais, após a leitura de títulos e resumos, foram selecionados 8 . Foram incluídos estudos em humanos e em animais que abordassem a temática, excluindose as revisões de literatura, relatos de caso e os estudos indisponíveis. Resultados: 3 estudos concluíram que existe uma forte associação dos genes amelogenina, enamelina, SCUBE1 e FAM83H com a HMI. 1 estudo sugeriu que mutações no gene STIM1 afetam o processo de maturação dos ameloblastos, enquanto outro estudo evidenciou que a interação epitelial entre fibronectina e integrina $\beta 1$ é importante para a formação do esmalte. 1 estudo inferiu que há uma maior prevalência de HMl em gêmeos monozigóticos em comparação a dizigóticos. 2 estudos concluíram que as variações nos genes relacionados à amelogênese estavam associadas ao desenvolvimento da HMI. Considerações Finais: Os estudos sugerem que existe uma influência genética sobre a etiologia da HMI, aliada aos fatores ambientais, socioeconômicos e as condições sistêmicas do indivíduo.

Palavras-chave: Genética, Hipoplasia do esmalte dentário, Dente molar, Incisivo.

\begin{abstract}
Objective: To verify the literature on the influence of genetic factors on the etiology of Molar-Incisor Hypomineralization (HMI). Methods: We searched for the descriptors registered in MeSH "genetics", "dental enamel hypoplasia", "molar" and "incisor" in the Pubmed database, connected by the Boolean operator "AND". In the period from 2009 to 2019,15 studies were found, of which, after reading the titles and abstracts, 8 were selected. Studies in humans and animals that addressed the topic were included, excluding literature reviews, reports case studies and unavailable studies. Results: 3 studies concluded that there is a strong association of the amelogenin, enamelin, SCUBE1 and FAM83H genes with HMI. 1 study suggested that mutations in the STIM1 gene affect the maturation process of ameloblasts, while another study showed that the epithelial interaction between fibronectin and $\beta 1$ integrin is important for enamel formation. 1 study inferred that there is
\end{abstract}

${ }^{1}$ Centro Universitário Católica de Quixadá (UNICATÓLICA), Quixadá - CE. *E-mail: lucaslinodo@gmail.com 2 Universidade Potiguar (UnP), Natal - RN.

3 Universidade Federal do Ceará (UFC), Fortaleza - CE. 
a higher prevalence of $\mathrm{IMH}$ in monozygotic twins compared to dizygotic twins. 2 studies concluded that variations in genes related to amelogenesis were associated with the development of IMH. Final Considerations: Studies suggest that there is a genetic influence on the etiology of HMI, combined with environmental, socioeconomic factors and the individual's systemic conditions.

Keywords: Genetics, Dental enamel hypoplasia, Molar tooth, Incisor.

\section{RESUMEN}

Objetivo: Consultar la literatura sobre la influencia de los factores genéticos en la etiología de la hipomineralización de incidentes molares (HMI). Métodos: Se buscaron los descriptores registrados en MeSH para "genética", "hipoplasia del esmalte dental", "molares" e "incisivos" en la base de datos Pubmed, conectados por el operador booleano "Y". En el período de 2009 a 2019, se encontraron 15 estudios, de los cuales, después de leer los títulos y los resúmenes, se seleccionaron 8 . Se incluyeron estudios en humanos y animales que abordaron el tema, excluyendo revisiones de literatura, informes de casos y estudios no disponibles. Resultados: 3 estudios concluyeron que existe una fuerte asociación de los genes amelogenina, enamelin, SCUBE1 y FAM83H con el HMI. 1 sugirió que las mutaciones en el gen STIM1 afectan el proceso de maduración de ameloblastos, mientras que otro estudio mostró que la interacción epitelial entre la fibronectina y la integrina $\beta 1$ es importante para la formación del esmalte. 1 estudio infirió que existe una mayor prevalencia de HIM en gemelos monocigóticos en comparación con los gemelos dicigóticos. 2 estudios concluyeron que las variaciones en los genes relacionados con la amelogénesis se asociaron con el desarrollo de HIM. Consideraciones finales: Los estudios sugieren que existe una influencia genética en la etiología del HMI, combinada con factores ambientales, socioeconómicos y condiciones sistémicas del individuo.

Palabras clave: Genética, Hipoplasia del esmalte dental, Diente molar, Incisivo.

\section{INTRODUÇÃO}

O termo Hipomineralização Molar-Incisivo (HMI) surgiu a partir dos estudos de Weerheijm KL, et al. (2001) como sendo uma anomalia do esmalte dentário de origem sistêmica, que pode envolver de um até quatro primeiros molares permanentes, e comumente acomete os incisivos permanentes. A patologia teve sua primasia identificada clinicamente no fim da década de 1970, na Suécia, no entanto até hoje sua etiologia permanece desconhecida (FERNANDES AS, et al., 2012).

A displasia pode ser observada no esmalte dentário como resultado de uma variedade de fatores socioambientais que influenciam diretamente no acometimento da HMI. Fatores estes que se estendem nos períodos pré-natal, complicações perinatais, pós-natal e durante a infância, que podem interferir de forma sistemática no desenvolvimento do esmalte dentário, assim como os problemas respiratórios, amigdalites e varicela (FERNANDES AS, et al., 2012; ASSUNÇÃO CM, et al., 2014). Ademais, recentemente tem sido proposto que os fatores genéticos também são uma das principais causas para o desenvolvimento da HMI (ALALUUSUA S, 2010). Por um olhar clínico, segundo Gonçalves FB (2011) a hipocalcificação do esmalte dentário apresenta zonas afetadas, e é provável identificar as lesões pela cor, sendo elas de coloração branca ou opaca, amarela ou castanha, que em geral são assimétricas. O diagnóstico diferencial da HMI pode ser dado em comparação a outros problemas no esmalte, como a fluorose dentária e amelogênese imperfeita. $\mathrm{Na} \mathrm{HMI}$, o esmalte normalmente apresenta-se mais frágil, ocorrendo uma maior possibilidade de fratura sobre intercessão de forças oriundas da mastigação, evidenciando a exposição dos tecidos dentinários e favorecem o aparecimento de cáries, sensibilidade dentária e, por fim, propicia uma higiene bucal insatisfatória (JALEVIK B e KLINGBERG G, 2002; RODD HD, et al., 2007).

Assim, revela-se que pode existir o aumento do risco de fraturas pós-erupção nos dentes com coloração mais escura (CROMBIE FA, et al., 2008). Ainda, como afirmaram Fernandes AS et al. (2012), nos esmaltes com lesões mais escuras, como a amarela e castanha, o elemento dentário apresentava porosidade mais acentuada que nos esmaltes de coloração branca e opaca. Os resultados dos estudos atestaram que, em 
sua avaliação clínica, a coloração do esmalte atribuiu um nível de severidade a lesão. Com isso, Alvarez L e Hermida $L$ (2009) explicaram que o esmalte afetado pela HMI desgasta-se continuamente, culminando na fratura dentária e, muitas vezes, criando cavidades na dentina que favorecem uma maior acumulação de placa bacteriana, podendo afetar severamente os molares.

No contexto brasileiro, Silva FM, et al. (2020) objetivaram salientar a prevalência de HMI no Brasil, baseado no pressuposto que achados anteriores afirmavam ser entre 2,5\% a 40,2\%. Dessa forma, investigaram 407 crianças entre 7 a 14 anos, onde os dados clínicos para HMI foram obtidos por um cirurgião-dentista devidamente calibrado, seguindo os critérios da Academia Europeia de Odontopediatria.

Com a pesquisa, perceberam que a maioria dos pacientes afetados eram do sexo masculino, com idade média de 10 anos, e prevalência no grupo de 14,5\%. Ademais, realizando-se uma meta-análise dos estudos sobre HMI realizados no Brasil, concedeu-se uma prevalência de 13,48\%.

Considerando o impacto da HMI na qualidade de vida de crianças brasileiras, Dantas-Neta NB, et al. (2016) realizaram um estudo com 594 escolares e seus pais/cuidadores, sendo 154 de escolas particulares e 440 do ensino público. A idade média dos participantes foi de 12,45 anos e a prevalência de HMI foi $18,4 \%$, apresentando-se superior nas escolas públicas.

Com o estudo, concluíram que, clinicamente e de acordo com a percepção dos pais, cuidadores e crianças, a ocorrência de $\mathrm{HMI}$ em escolares tem impacto negativo nos sintomas orais e limitação funcional, em comparação com escolares sem HMI.

Cunha NA (2015) afirma que, de acordo com o grau de severidade da lesão, pode apresentar inúmeras alterações do grau da coloração, sua estrutura e forma dentária. Ainda, de acordo com Cunha NA (2015), dependendo o nível da patologia, se opta por modalidades distintas de terapia, onde devem ser dispostas cada necessidade individual dos pacientes.

Já no que diz respeito a prevenção, deve-se considerar a educação em saúde bucal como importante ferramenta, assim como também fazer aplicação de selantes, cimento de ionômero de vidro, materiais restauradores provisórios e restaurações diretas em resina composta (CROMBIE F, et al., 2009; COSTASILVA CM, et al., 2015).

Dessa forma, em virtude da HMI representar uma condição dentária que apresenta diversos graus e possui uma etiologia complexa, o presente artigo tem como objetivo revisar a literatura acerca da influência dos fatores genéticos na etiologia da HMl, evidenciando a relação com os genes e seus fatores causais, seu diagnóstico diferencial e possíveis tratamentos.

\section{MÉTODOS}

Pesquisaram-se os descritores devidamente cadastrados no MeSH e DeCS "genetics", "dental enamel hypoplasia", "molar" e "incisor" na base de dados PubMed, conectados pelo operador booleano "AND". Em uma busca geral, sem restrição de tempo, puderam ser encontrados 22 estudos.

Já nos últimos 10 anos, contemplando o período entre 01 de janeiro de 2009 a 31 de dezembro de 2019, encontraram-se 15 estudos, dos quais, após a leitura criteriosa de títulos e resumos, foram selecionados 8 . Foram incluídos estudos em humanos e em animais na língua inglesa que abordassem a relação dos fatores genéticos com a etiologia da hipomineralização molar-incisivo, excluindo-se as revisões de literatura, relatos de caso, artigos que abordassem outras displasias de esmalte e os estudos indisponíveis.

Dos estudos incluídos na revisão bibliográfica, quatro tratavam-se de estudos em animais, um referia-se a um estudo caso-controle, um estudo de coorte, um estudo longitudinal e, por fim, um estudo transversal. Já no que concerne aos estudos que foram excluídos da revisão, dois estudos eram relatos de caso, um estudo trata-se de uma revisão de literatura, dois estudos não abordavam o assunto e outros dois estudos encontravam-se indisponíveis (Figura 1). 
Figura 1 - Fluxograma metodológico.

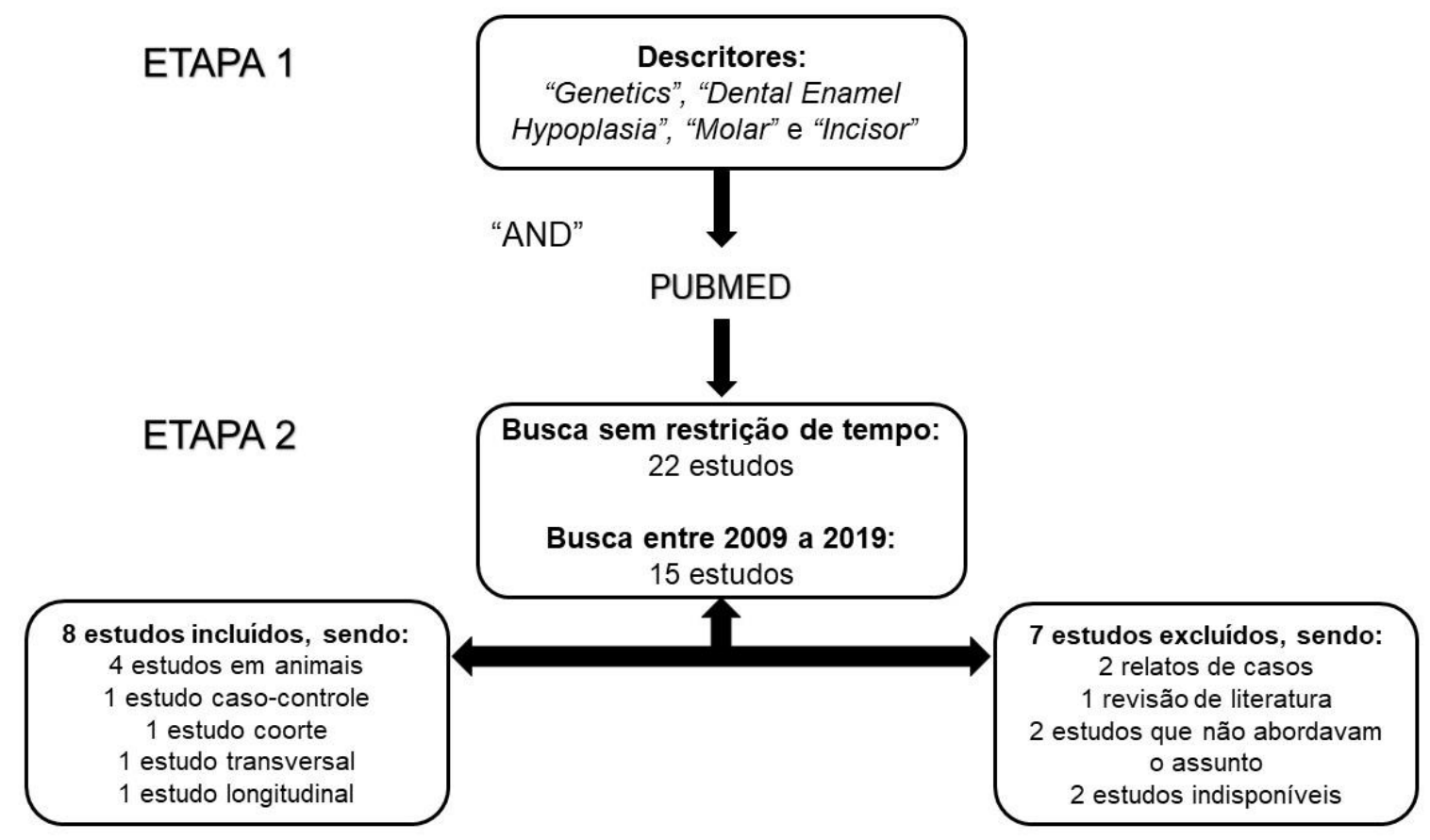

Fonte: Oliveira LL, et al., 2020.

\section{RESULTADOS}

Os resultados obtidos na busca bibliográfica, a partir dos critérios de inclusão e exclusão, estão compilados na forma de quadro (Quadro 1). 
Quadro 1 - Resultados da busca bibliográfica.

\begin{tabular}{|c|c|c|c|}
\hline Autor/Ano & Título & $\begin{array}{l}\text { Tipo de } \\
\text { estudo }\end{array}$ & $\begin{array}{l}\text { Principais } \\
\text { resultados }\end{array}$ \\
\hline $\begin{array}{l}\text { Lee MJ, et } \\
\text { al. (2009) }\end{array}$ & $\begin{array}{l}\text { Expression patterns of the } \\
\text { Fam83h gene during murine } \\
\text { tooth development }\end{array}$ & Animal & $\begin{array}{l}\text { O gene FAM83H está associado ao processo } \\
\text { de desenvolvimento da HMI, sendo detectado } \\
\text { nos ameloblastos no estágio pré-secretório até } \\
\text { o secretório }\end{array}$ \\
\hline $\begin{array}{l}\text { Jeremias } \\
\text { F, et al. } \\
\text { (2013) }\end{array}$ & $\begin{array}{l}\text { Genes expressed in dental } \\
\text { enamel development are } \\
\text { associated with molar-incisor } \\
\text { hypomineralization }\end{array}$ & $\begin{array}{l}\text { Caso- } \\
\text { controle }\end{array}$ & $\begin{array}{l}\text { Os genes enamelina, amelogenina e proteína } \\
11 \text { de interação com tuftelina estavam } \\
\text { relacionados a etiologia da HMI }\end{array}$ \\
\hline $\begin{array}{l}\text { Kühnisch } \\
\text { J, et al. } \\
(2014)\end{array}$ & $\begin{array}{l}\text { Genome-wide association study } \\
\text { (GWAS) for molar-incisor } \\
\text { hypomineralization (HMI) }\end{array}$ & te & $\begin{array}{l}\text { SCUBE } 1 \text { no cromossomo } 22 \text { está associado } \\
\text { como um possível locus de desenvolvimento da } \\
\text { HMI }\end{array}$ \\
\hline $\begin{array}{l}\text { Saito K, et } \\
\text { al. (2015) }\end{array}$ & $\begin{array}{l}\text { Interaction between fibronectin } \\
\text { and } \beta 1 \text { integrin is essential for } \\
\text { tooth development }\end{array}$ & & $\begin{array}{l}\text { Alguma deleção ectodérmica no processo de } \\
\text { interação epitelial entre fibronectina e integrina } \\
\beta 1 \text { pode comprometer o processo de formação } \\
\text { do esmalte dentário }\end{array}$ \\
\hline $\begin{array}{l}\text { Jeremias } \\
\text { F, et al. } \\
(2016)\end{array}$ & $\begin{array}{r}\text { Fam } \\
\text { associat } \\
\text { hyp }\end{array}$ & $\begin{array}{l}\text { Longitud } \\
\text { inal }\end{array}$ & $\begin{array}{l}\text { Variações nos genes relacionados à } \\
\text { amelogênese estavam envolvidos no processo } \\
\text { de desenvolvimento da HMI }\end{array}$ \\
\hline $\begin{array}{l}\text { Furukawa } \\
\text { Y, et al. } \\
(2017)\end{array}$ & $\begin{array}{l}\text { Stim } 1 \text { regulates enamel } \\
\text { mineralization and ameloblast } \\
\text { modulation }\end{array}$ & al & $\begin{array}{l}\text { A SOCE é fundamental para a mineralização } \\
\text { adequada do esmalte, indicando que, } \\
\text { principalmente, alguma deleção ectodérmica } \\
\text { no gene STIM1 pode causar HMI. }\end{array}$ \\
\hline $\begin{array}{l}\text { Morkmued } \\
\text { S, et al. } \\
(2017)\end{array}$ & $\begin{array}{c}\text { Enamel and dental anomalies } \\
\text { in latent-transforming growth } \\
\text { factor beta-binding protein } 3 \\
\text { mutant mice }\end{array}$ & nimal & $\begin{array}{l}\text { A proteína de ligação beta } 3 \text { do fator de } \\
\text { crescimento transformador latente é essencial } \\
\text { para a diferenciação dos ameloblastos e para a } \\
\text { formação de prismas de esmaltes decussantes. }\end{array}$ \\
\hline $\begin{array}{l}\text { Texeira } \\
\text { RJ, et al. } \\
(2018)\end{array}$ & $\begin{array}{l}\text { Exploring the association } \\
\text { between genetic and } \\
\text { environmetal factors and molar } \\
\text { incisor hypomineralization: } \\
\text { evidence from a twin study }\end{array}$ & $\begin{array}{c}\text { Transve } \\
\text { rsal }\end{array}$ & $\begin{array}{l}\text { Houve maior concordância na ocorrência de } \\
\text { HMI em gêmeos monozigóticos em } \\
\text { comparação aos dizigóticos, indicando uma } \\
\text { influência genética sobre a doença }\end{array}$ \\
\hline
\end{tabular}

Fonte: Oliveira LL, et al., 2020.

\section{DISCUSSÃO}

A HMI inicialmente foi descrita como um problema idiopático, porém, com o decorrer dos anos e os estudos mais relacionados com essa área, observou-se que esta condição relacionava-se com diversos fatores etiológicos associados a distúrbios nas fases de maturação do esmalte, independente do uso do flúor ou a amamentação.

Estudos realizados em ratos afirmaram que quando expostos a uma dose diária de bisfenol, os animais desenvolveram uma condição de hipomineralização do esmalte. Acredita-se que isso ocorreu devido a modulação da expressão de dois genes, e a preferência clínica marcante por molares e incisivos pode estar relacionada com agenesia, microdontia e fendas orais.

Os casos desde agenesia a dimensões dentárias menores estavam relacionados com uma alteração da proteína PAX9 podendo modificar diversos grupos de dentes. A HMI, além dos primeiros molares e incisivos permanentes, em alguns casos raros, pode acometer os segundos molares decíduos e/ou permanentes, caninos e pré-molares (VIEIRA AR e KUP E, 2016). 
Corroborando com esses achados, Silva MJ, et al. (2016) realizaram um estudo com profissionais de diversas especialidades e alunos de graduação de Odontologia na Arábia Saudita e expuseram que a hipomineralização molar-incisivo é o segundo maior problema de saúde pública, podendo ainda estar relacionado com a localização dos pacientes, sendo $61,8 \%$ moradores da zona urbana $(61,8 \%)$ e $44,2 \%$ residentes em zona rural. No entanto, profissionais recém-formados não apresentavam ter segurança em diagnosticar tal condição, sendo necessário mais formações e treinamentos adicionais, independentemente do tempo de experiência dos mesmos. Já os alunos de graduação apresentaram ter pouco contato com a HMI, de acordo com o tempo de formação, porém demonstraram ter maior segurança ao realizar o diagnóstico de HMI, em comparação com os profissionais.

Nesse sentido, Cabral RN (2017) descreveu um novo sistema de classificação da HMI baseado na gravidade dos defeitos, e avaliou a confiabilidade intraexaminadora do sistema. Este novo sistema, por sua vez, ainda abrange a descrição dos defeitos causados pela HMI, e não somente de acordo com suas características clínicas, mas também considerando diferentes níveis de gravidade.

O novo sistema é baseado em 10 códigos, indo desde opacidades demarcadas até a extração dentária devido à $\mathrm{HMI}$, contribuindo para reportar a gravidade da HMI de forma padronizada para evitar discrepâncias significativas em estudos epidemiológicos. O autor percebeu que o novo sistema tornou-se uma ferramenta de diagnóstico a ser utilizada no consultório odontológico e em estudos de campo, sendo testado em um estudo longitudinal realizado em 6 escolas localizadas em Paranoá, no Distrito Federal.

A amostra compreendeu 179 crianças, com idade entre 7 a 12 anos, sendo estas incluídas e avaliadas de acordo com o novo sistema em exames repetidos durante o período de 2014 a 2016. A confiabilidade do novo sistema foi testada por meio de porcentagens de concordância e valores de kappa. Como resultado, as porcentagens de concordância em relação ao diagnóstico da HMI variaram de 94,6 a 97,9\%.

Considerando os dados intraexaminadores, os valores de kappa variaram de 0,82 a 0,88 . Dessa forma, concluiu-se que o novo sistema testado foi capaz de fornecer informações detalhadas sobre a gravidade da condição, apresentando alta confiabilidade, salientando que, em relação à gravidade, a HMl é uma condição progressiva.

Sabe-se que a coloração das lesões influenciam na ocorrência de fraturas. Assim, em um novo estudo, Cabral RN (2017) realizou uma pesquisa longitudinal durante 36 meses com crianças de 7 a 12 anos $(n=$ 240), diagnosticadas previamente com HMI, objetivando avaliar se a cor das opacidades influenciava na ocorrência de fraturas pós-eruptivas e se ocorria a regressão durante o período.

Foi utilizado o novo sistema para classificação da HMI que visa diferenciar as lesões de acordo com a gravidade, diferenciando as brancas das amarelas e marrons, levando em consideração que as lesões amarelas e marrons têm uma maior chance de progredir para quebras pós-eruptivas quando comparadas com as brancas. Além disso, classificou-se também as quebras pós-eruptivas em quebras restritas ao esmalte ou com exposição dentinária, assim como a presença de restaurações atípicas com ou sem defeito marginal e, por último, casos de dentes extraídos por conta da HMI.

Após 12, 18, 24 e 36 meses, foi realizado o acompanhamento, observando que, em relação a gravidade da $\mathrm{HMI}$, em primeiros molares permanentes há uma maior prevalência de casos graves $(14,84 \%)$ do que quando comparado aos incisivos permanentes e uma maior prevalência de casos leves $(96,47 \%)$ em incisivos permanentes. Em relação a progressão de dentes com HMI para quebras pós-eruptivas, as amarelas e marrons tem maiores chances de acontecerem do que as brancas, porém ressalva-se que ambas possuem a capacidade de progredir.

Ademais, estudos também tem demonstrado que a HMI pode ter uma relação com a doença cárie. Jeremias F, et al. (2010) realizaram um levantamento epidemiológico utilizando 1157 escolares, com 6 a 12 anos, para determinar a predominância e o grau de severidade da $\mathrm{HMI}$ e sua associação com a cárie. Para isso, foram avaliados os índices CPO-D e ceo-d e foram utilizados testes estatísticos descritivos para tabulação e análise dos dados, onde observou-se que a prevalência da HMl foi de $12,3 \%$ e o sexo mais afetado foi o feminino. 
Além disso, a arcada superior foi mais acometida, onde os primeiros molares permanentes superiores foram mais atingidos, seguidos pelos molares inferiores e incisivos centrais superiores. As crianças com HMI apresentaram um CPO-D de 0,89 e o ceo-d de 1,24, maiores que os valores do grupo não afetado $(0,43 \mathrm{e}$ $1,03)$. O grau de severidade leve foi o mais predominante e nas crianças com $\mathrm{HMI}$ a cárie afetou mais a dentição permanente.

Corroborando com os resultados do estudo acima, Costa-Silva CM, et al. (2010), através de outro estudo epidemiológico, investigaram a presença da HMI em escolares, analisando sua relação com cárie e fatores socioeconômicos, porém, diferentemente do estudo anterior, também foram levados em consideração os fatores demográficos. Para diagnosticar a condição, foram empregados os parâmetros da EAPD (European Academy of Paediatric Dentistry) e para a cárie, o CPO-D. Além disso, os pais responderam um questionário acerca das condições socioeconômicas e os dados demográficos foram obtidos no momento do exame clínico.

Como resultados, a prevalência da HMI foi de $19,8 \%$ e de cárie foi de $55,9 \%$, e as crianças com HMI manifestaram maior susceptibilidade à cárie na dentição permanente. Além disso, os fatores socioeconômicos não foram associados à presença da HMI. No entanto, com relação aos fatores demográficos, foi possível observar que crianças acima de 10 anos residentes na zona rural são mais vulneráveis à HMI e cárie.

Desse modo, no que concerne aos fatores genéticos como possível etiologia para a HMI, Texeira RJ, et al. (2018) avaliaram, através de um estudo observacional, a incidência de HMI em gêmeos monozigóticos e dizigóticos de 8 a 15 anos de idade que apresentassem o 1ํㅡㄹ molar permanente totalmente erupcionado.

Foram incluídos 167 pares de gêmeos, sendo 98 indivíduos diagnosticados com HMI. Eles concluíram que existe uma influência genética sobre a doença, uma vez que houve uma maior concordância da ocorrência de HMl em gemêos monozigóticos, porém associaram sua etiologia também aos fatores ambientais e a ocorrência de hemorragia durante o parto.

Ainda, Furukawa Y, et al. (2017) e Morkmued S, et al. (2017), em ensaios com ratos, inferiram que a SOCE e a proteína de ligação beta 3 do fator de crescimento transformador latente (LTGB-3) são essenciais para a mineralização adequada do esmalte, inferindo que o gene STIM1 é responsável por regular a mineralização do esmalte e a modulação dos ameloblastos, sendo que qualquer deleção ectordérmica nesse gene influencia na ocorrência de HMI. Nestes estudos os resultados foram obtidos através de PCR quantitativo, tomografia computadorizada, histologia e microscopia eletrônica de varredura.

Já em um estudo com humanos, Jeremias F, et al. (2016) extraíram o DNA a partir de células bucais de 391 indivíduos que eram familiares, onde polimorfismos de nucleotídeo único (SNPs) foram investigados em 21 genes relacionados à amelogênese utilizando a plataforma de genotipagem TaqMan OpenArray com os indivíduos não afetados, com status desconhecido e afetados por HMI. Com isso, concluíram que variações nos genes relacionados à amelogênese estavam envolvidos na etiologia da $\mathrm{HMI}$.

Saito K, et al. (2015), através de um ensaio em ratos, perceberam que a interação entre fibronectina e integrina $\beta 1$ é importante para o processo de formação do esmalte dentário, bem como na diferenciação dos ameloblastos, uma vez que a fibronectina apresenta papel de adesão no estágio de maturação final dos ameloblastos, atuando como organizadoras da matriz extracelular durante a amelogênese.

Kühnisch J, et al. (2014), em estudo de coorte, avaliaram SNPs através de uma associação ampla de genoma, e perceberam que o gene SCUBE1 no cromossomo 22 estava associado como um possível locus de desenvolvimento da $\mathrm{HMI}$, inferindo também que os genes ameloblastina, amelotina, tuftelina e MMP-20 não se relacionaram à etiologia da $\mathrm{HMI}$.

Por outro lado, Jeremias F, et al. (2013) agora em um estudo caso-controle avaliaram, através de genotipagem pelo método de TaqMan, onze marcadores em cinco genes, sendo estes ameloblastina, amelogenina, enamelina, tuftelina e proteína 11 de interação com tuftelina, associados às experiências de cárie. Com isso, concluíram que o gene enamelina esteve relacionado ao desenvolvimento da HMI independente da experiência de cárie, enquanto amelogenina e proteína 11 de interação com tuftelina estiveram relacionados aos dois processos. 
Lee MJ, et al. (2009), em um ensaio com ratos utilizando hibridização secional seriada em série por sonda de RNA marcada com DIG, inferiram que o gene FAM83H estava associado ao processo de desenvolvimento da $\mathrm{HMI}$, sendo detectado nos ameloblastos no estágio pré-secretório até o secretório, assim como nos odontoblastos e osso alveolar circundante. Torna-se necessário, portanto, tratar a condição desses pacientes de forma adequada para cada caso. Baseado nisso, Vilani PN, et al. (2014), em um relato de caso de um paciente com 22 anos de idade diagnosticado com HMI, destacou a importância do diagnóstico correto. $\mathrm{O}$ paciente havia realizado procedimentos restauradores com resina composta e, após uma anamnese detalhada, constatou-se que o mesmo apresentou quadro de bronquite crônica com picos de febre alta, sendo esta doença sistêmica possível etiologia da HMI.

Optou-se como tratamento para tal paciente restaurações com cimento de ionômero de vidro RIVA light cure, preservando o esmalte remanescente saudável. Os autores inferiram que uma boa anamnese e um diagnóstico precoce e preciso são fatores cruciais para a redução dos danos causados no substrato dentário. Assim, tendo em vista um diagnóstico precoce e a escolha da melhor opção de tratamento, Assunção CM, et al. (2014) relataram o caso de um paciente pediátrico de 7 anos de idade com queixa estética e de sensibilidade dentária que fora diagnosticado com HMI, sendo esta com etiologia interligada a picos de febre. Considerando a idade e a perca dentária, optou-se por intervenção restauradora com resina composta e a fluoretação diária, além de consultas periodicamente.

Entretanto, devido à falta de comprometimento a ida às consultas, o tratamento tornou-se ineficaz, sendo necessárias novas intervenções, ressaltando a importância do comprometimento dos pais com o tratamento de crianças com HMI. Em contrapartida, Côrtes LC, et al. (2015) relataram o caso de um paciente pediátrico com 8 anos de idade que apresentava comprometimento para com as manutenções, em que a conduta de tratamento utilizada foi aplicação única de verniz de fluoreto de sódio a $5 \%$ associada a profilaxia com pedra pomes, procedimento restaurador e bochecho com fluoreto de sódio a $2 \%$ por 15 dias após escovação noturna. Concluíram que o tratamento surtiu efeitos, observando-se que, após 3 meses, o paciente apresentava bom selamento marginal, ausência de pigmentação, assim como ausência de dor e sensibilidade dental.

Com isso, torna-se evidente que a HMl é uma condição dentária que apresenta uma etiologia ampla e complexa. Por conseguinte, essa complexidade é refletida na dificuldade de diagnóstico e no tratamento a ser adotado (DALY D e WALDRON JM, 2009). A qualidade da adesão dos materiais restauradores nos dentes afetados com HMl ainda é desconhecida, devido aos seus episódios de diferenciação morfológica. Dessa forma, tal fator implica que os pacientes que são submetidos a tratamentos restauradores sejam acompanhados periodicamente, visando a longevidade dessas restaurações e um tratamento eficaz (WILLMOTT NS, et al., 2008).

\section{CONSIDERAÇÕES FINAIS}

Em suma, os estudos evidenciaram que existe uma influência genética sobre a etiologia da HMI, porém seus fatores causais também estão associados ao ambiente, condições socioeconômicas e sistêmicas do indivíduo, indicando uma etiologia complexa e multifatorial. No que tange os fatores genéticos, sendo o enfoque principal do presente estudo, os estudos elucidaram que os principais genes relacionados à etiologia da amelogênese também podem estar presentes na patogênese da HMI, apresentando amelogenina, ameloblastina, enamelina e tuftelina como os genes comumente associados. Assim, inferiram que qualquer deleção ectodérmica nesses genes pode levar ao desenvolvimento dessa condição.

\section{REFERÊNCIAS}

1. ALALUUSUA S. Aetiology of molar-incisor hypomineralisation: a systematic review. European Archives of Paediatric Dentistry, 2010; 11(2): 53-58.

2. ALVAREZ L, HERMIDA L. Hipomineralización molar-incisiva (MIH): una patología emergente. Odontoestomatología, 2009; 11(12): 4-11.

REAS/EJCH | Vol.12(8) | e3336 | DOI: https://doi.org/10.25248/reas.e3336.2020 Página 8 de 9 
3. ASSUNÇÃO CM, et al. Hipomineralização de molar-incisivo (HMI): relato de caso e acompanhamento de tratamento restaurador. Revista da associaçãopaulista de cirurgiõesdentistas. São Paulo, 2014; 68(4): 346-350.

4. CABRAL RN. Novo sistema de detecção para a hipomineralização molar incisivo: diagnóstico, progressão dos defeitos e decisão de tratamento, 2017.

5. CÔRTES LCA. Protocolo de tratamento de hipomineralização molar-incisivo em odontopediatria: relato de caso clínico. Tese de Doutorado- Universidadelbirapuera, 2015.

6. COSTA SILVA CM, et al. Prevalência de Hipomineralização Molar incisivo e sua relação com a cárie dentária, necessidades de tratamento, fatores socioeconômicos e demográficos. Faculdade de Odontologia de Araraquara, 2010.

7. CROMBIE F, et al. Aetiology of molar-incisor hypomineralization: a critical review. International Journal of Paediatric Dentistry, 2009; 19(2): 73-83.

8. CROMBIE FA, et al. Molar incisor hypomineralization: a survey of members of the Australian and New Zealand Society of Paediatric Dentistry. Australian dental jornal, 2008; 53(2): 160-166.

9. CUNHA NA. Alternativas Terapeuticas na Abordagem da Hipomineralização Incisivo-molar. Tese de Doutorado Faculdade Fernando Pessoa, Faculdade de Ciencias da Saúde. Porto-Portugal, 2015.

10. DA COSTA-SILVA CM, et al. Increase in severity of molar-incisor hypomineralization and its relationship with the colour of enamel opacity: a prospective cohort study. International journal of paediatric dentistry, 2011; 21(5): 333341.

11. DALY D, WALDRON JM. Molar incisor hypomineralisation: clinical management of the young patient. $\mathrm{J}$ of the Irish Dental Association, 2009; 55(2): 83-86.

12. DANTAS-NETA NB, et al. Impact of molar-incisor hypomineralization on oral health-related quality of life in schoolchildren. Brazilian oral research, 2016; 30(1).

13. FERNANDES AS, et al. Hipomineralizacão incisivo-molar: uma revisão da literatura. Revista Portuguesa de Estomatologia, MedicinaDentária e CirurgiaMaxilofacial, 2012; 53(4): 258-262.

14. FURUKAWA Y, et al. Stim1 regulates enamel mineralization and ameloblast modulation. Journal of dental research, 2017; 96(12): 1422-1429.

15. GONÇALVES FB. Hipomineralização Incisivo-molar: Prevalência e Etiologia. Tese de Doutorado - Universidade Fernando Pessoa, Porto, Portugal.

16. JALEVIK B, KLINGBERG G. Dental treatment, dental fear and behaviour management problems in children with severe enamel hypomineralization of their permanent first molars. International Journal of Paediatric Dentistry, 2002; 12(1): 24-32.

17. JEREMIAS F, et al. Family-based genetic association for molar-incisor hypomineralization. Caries research, 2016; 50(3): 310-318.

18. JEREMIAS F, et al. Genes expressed in dental enamel development are associated with molar-incisor hypomineralization. Archives of oral biology, 2013; 58(10): 1434-1442.

19. JEREMIAS F, et al. Hipominaralização molar-incisivo em escolares: prevalência, severidade e sua relação com a cárie dentária. Faculdade de Odontologia de Araraquara, 2010.

20. KUHNISCH J, et al. Genome-wide association study (GWAS) for molar-incisor hypomineralization (MIH). Clinical oral investigations, 2014; 18(2): 677-682.

21. LEE MJ, et al. Expression patterns of the Fam83h gene during murine tooth development. Archives of oral biology, 2009; 54(9): 846-850.

22. MORKMUED S, et al. Enamel and dental anomalies in latent-transforming growth factor beta-binding protein 3 mutant mice. European journal of oral sciences, 2017; 125(1): 8-17.

23. RODD HD, et al. Pulpal status of hypomineralized permanent molars. Pediatric dentistry, 2007; 29(6): 514-520.

24. SAITO K, et al. Interaction between fibronectin and $\beta 1$ integrin is essential for tooth development. PLoS One, 2015; 10(4).

25. SILVA FM, et al. Defining the Prevalence of Molar Incisor Hypomineralization in Brazil. Pesquisa Brasileira em Odontopediatria e Clínica Integrada, 2020; 20.

26. SILVA MJ, et al. Knowledge and attitudes regarding molar incisor hypomineralisation amongst Saudi Arabian dental practitioners and dental students. European Archives of Paediatric Dentistry, 2016; 14(4): 215-222.

27. TEIXEIRA RJPB, et al. Exploring the association between genetic and environmental factors and molar incisor hypomineralization: evidence from a twin study. International journal of paediatric dentistry, 2018; 28(2): $198-206$.

28. VIEIRA AR, KUP E. On the etiology of molar-incisor hypomineralization. Caries research, 2016; 50(2): $166-169$.

29. VILANI PNL, et al. Hipomineralização Molar Incisivo: Relato de caso clínico. Revista da Faculdade de Odontologia de Lins, 2014; 24(1): 64-68.

30. WEERHEIJM KL, et al. Molar-incisor hypomineralisation. Caries research, 2001; 35(5): 390-391.

31. WILLMOTT NS, et al. Molar-incisor-hypomineralisation: a literature review. European Archives of Paediatric Dentistry, 2008; 9(4): 172-179. 